\title{
Adhesive resistance of a copaiba oil-based dentin biomodifier
}

Maria Fulgência Costa Lima BANDEIRA(a) (D)

Alinne Lessa FREITAS(a) (D)

Manuela de Souza Cruz MENEZES(a) (D)

Jardel dos Santos SILVA ${ }^{(a)}$ (i)

Gesom Avohai Dias SOMBRA(a) (1)

Eliane Avany Malveira ARAÚJO(a) (1)

Carina TODA ${ }^{(a)}$ (D)

Ana Regina Casaroto MORESCHI(a) (D)

Nikeila Chacon de Oliveira CONDE(a) (C)

(a) Universidade Federal do Amazonas -

UFAM, School of Dentistry, Manaus, AM, Brazil.

Declaration of Interests: The authors certify that they have no commercial or associative interest that represents a conflict of interest in connection with the manuscript.

Corresponding Author:

Ana Regina Casaroto Moreschi

E-mail:ana_casaroto@yahoo.com.br

ht1ps://doi.org/10.1590/1807-3107bor-2020.vol34.0001

Submitted: April 30, 2019

Accepted for publication: November 1, 2019

Last revision: November 25, 2019
Abstract: This study analyzed the effect of prior application of copaiba oil (CO) emulsions as a dentin cleaning substance on microleakage and microtensile adhesive strength. Twenty-five premolars and sixty-four molars were used for microleakage and microtensile assays. For the microleakage assays, specimens with standard class $\mathrm{V}$ cavities were divided $(n=5)$, according to the tested CO emulsions: CO10\%X, $\mathrm{CO} 10 \% \mathrm{Y}$, and $\mathrm{CO} 10 \% \mathrm{Z}$, as well as chlorhexidine $2 \%$ (CHX) and distilled water (DW), as positive and negative controls, respectively. Restorations were performed using the Adper Single Bond ${ }^{\circledR}$ and/or Clearfil SE Bond ${ }^{\circledR}$ systems. Cervical, occlusal, distal and mesial sections were assessed for tracer penetration degree at the composite/tooth interface. For the microtensile assay, healthy molars were divided into sixteen groups, in which artificial caries were induced in half of the groups. Dentin surfaces were treated with $\mathrm{CO} 10 \% \mathrm{X}$ and $\mathrm{CO} 10 \% \mathrm{Y}, \mathrm{CHX}$ and DW. Microtensile bond strength was measured by fixing each sample to the plate of a universal testing machine operated at a speed of $0.5 \mathrm{~mm} /$ minute until failure. Dentin treated with CO10\%X showed a lower infiltration rate than dentin treated with the other $\mathrm{CO}$ emulsions, CHX2\% and DW. According to the microtensile assay, both healthy and affected dentin treated with $\mathrm{CO} 10 \% \mathrm{X}$ and Adper Single Bond ${ }^{\circledR}$ adhesive system presented higher adhesive strength. CO emulsion, used as a dentin biomodifier, interfered positively in microleakage and improved adhesive strength after acid etching in the Adper Single Bond ${ }^{\circledR}$ adhesive system, or before applying the Clearfil SE Bond ${ }^{\circledR}$ self-etching system.

Keywords: Fabaceae; Phytotherapy; Molar; Chlorhexidine.

\section{Introduction}

The practice of using medicinal plants for curative treatments of diseases is as old as the human species. Knowledge of the therapeutic properties of these plants has been transmitted through generations, arousing the interest of researchers. In this respect, Brazil has the advantage of having the greatest biodiversity in the world, especially concentrated in the Amazon region. Another positive feature is its genetic heritage of having great potential to develop new herbal products at a low cost, and with effects similar to traditional products. ${ }^{1}$ 
The copaiba tree is a common species native to Latin America and West Africa, and can be found in Brazil's Southeast, Midwest and Amazon regions. Copaifera multijuga Hayne oleoresin, popularly known as copaiba oil (CO), is an exudate secreted from the trunk of these trees. $\mathrm{CO}$ has antiseptic, anti-inflammatory, antibacterial and antifungal properties, and has been used for over 500 years to treat wounds, as an alternative to other traditional treatments. ${ }^{2}$ In dentistry, CO has presented promising results in dentin adhesion of restorative materials to a dental structure. ${ }^{3}$

According to Black, ${ }^{4}$ dentin cavity cleaning represents the last stage of cavity preparation, and is recommended before insertion of the restorative material. Different agents can be used to remove residues from cavity preparation, such as $\mathrm{CO}$, formulated in an emulsion investigated in a study by Bandeira et al. ${ }^{3}$

Currently, composite resin stands out particularly in restorative dentistry, owing to its excellent aesthetic properties. However, composite resin is a polymeric material with the main disadvantage of polymerization contraction. This attribute poses drawbacks, such as microcracks and marginal microleakage, which promote postoperative sensitivity, marginal discoloration, secondary caries, margin breaking restoration and pulpal pathology. 5,6

Treatment of the dentin surface before application of the adhesive system influences dentin adhesion significantly. ${ }^{7}$ Moreover, application of the adhesive system to dentin substrate conditioned by phosphoric acid can activate matrix metalloproteinases (MMPs), and initiate an autolytic phenomenon that will affect the hybrid layer. ${ }^{8,9}$ Since the binding process occurs through collagen encapsulation by the adhesive system, the MMPs must be inhibited in order to preserve the adhesive interface from proteolytic degradation. ${ }^{10}$ Introduction of certain solutions into the adhesive interface helps preserve this area, highlighting chlorhexidine ( $\mathrm{CHX}$ ) as the most commonly used substance. ${ }^{9}$

CHX may be used as a preventive strategy against collagen fiber degradation. In addition to its disinfecting effect, $\mathrm{CHX}$ acts as a MMP inhibitor. ${ }^{9}$ In addition, recent studies have indicated $\mathrm{CO}$ emulsion as a dentin biomodifier, with potential action to inhibit MMP-2 and MMP-9, thereby improving dentin adhesion to restorative material. ${ }^{3}$

$\mathrm{CO}$ emulsion can be considered a dentin biomodifying agent. Its antibacterial, antifungal, antineoplastic and antiproteolytic biological properties stand out, and it can be used in deep cavities, unlike currently marketed materials, which are not indicated for such a procedure. Given its broad spectrum of activities, the aim of the present study was to analyze the effect of prior application of $\mathrm{CO}$ emulsions as dentin cleaning substances on microleakage and on microtensile adhesive strength. The null hypotheses were: a) marginal microleakage would not be affected by the cleaning substance; $b$ ) adhesive strength would not be affected by the cleaning substance, the dentin substrate, or the adhesive system.

\section{Methodology}

Following approval of the research protocol by the university ethics committee, eighty-nine extracted human premolars or third molars were collected. The teeth were extracted for orthodontic reasons and were free of any caries, cracks or previous restorations. Twenty-five premolars were used for the microleakage assay, and sixty-four third molars, for the microtensile assay.

\section{Copaiba oil-resin and emulsion formulations}

C. multijuga oil-resin was obtained from the National Institute of Amazonian Research (INPA, Amazon, Brazil), along with exsiccatae, a collection of dried specimens deposited in the herbarium of this institution. CO emulsions at $10 \%$, with three different concentrations of the preservative ( $\mathrm{X}, \mathrm{Y}$ and $\mathrm{Z}$ ) were processed at the School of Dentistry), according to methodology proposed by Bandeira et al. ${ }^{11}$

\section{Microleakage assay}

Standard Class V cavities with a mesiodistal width of $3 \mathrm{~mm}$, occlusogingival height of $2 \mathrm{~mm}$, and axial depth of $1.5 \mathrm{~mm}$ were prepared on vestibular and lingual surfaces. After etching with $37 \%$ phosphoric acid (3M ESPE, St Paul, USA), the specimens were 
randomly divided into five equal groups $(n=5)$, according to the $\mathrm{CO}$ test emulsions for cleaning the dentin surface, as follows: $\mathrm{CO} 10 \% \mathrm{X}, \mathrm{CO} 10 \% \mathrm{Y}$, and CO10\%Z. Chlorhexidine 2\% (CHX) and distilled water (DW) were used as positive and negative controls, respectively. Following the manufacturer's guidelines (Table 1), Adper Single Bond ${ }^{\circledR}$ adhesive system and Filtek ${ }^{\circledR}$ Z350 composite resin were used for cavity restoration. Then, the teeth were polished and immersed in a physiological solution. After completing the restoration, the specimens were incubated at $37^{\circ} \mathrm{C}$ for $24 \mathrm{~h}$. The teeth were immersed in an aqueous $50 \%$ silver nitrate solution $\left(\mathrm{AgNO}_{3}\right)$ in a dark and closed environment for $2 \mathrm{~h}$. Then, the specimens were placed in a pure developer solution (Eastman-Kodak) under fluorescent light for $16 \mathrm{~h}$ to reduce silver ions. The teeth were sectioned with a water-cooled diamond wheel saw (BUEHLER). First, the teeth were sectioned in the mesiodistal direction to obtain buccal and lingual halves together with the restoration. Then, the two halves were sectioned longitudinally through the center of the restoration, resulting in mesial and distal hemi sections. The cervical, occlusal, distal and mesial sections were blindly assessed to determine the penetration degree of the tracer agent, using a stereomicroscope (Carl Zeiss, Oberkochen, Germany) at 20x magnification. Tracer penetration at the

Table 1. Materials used in the study

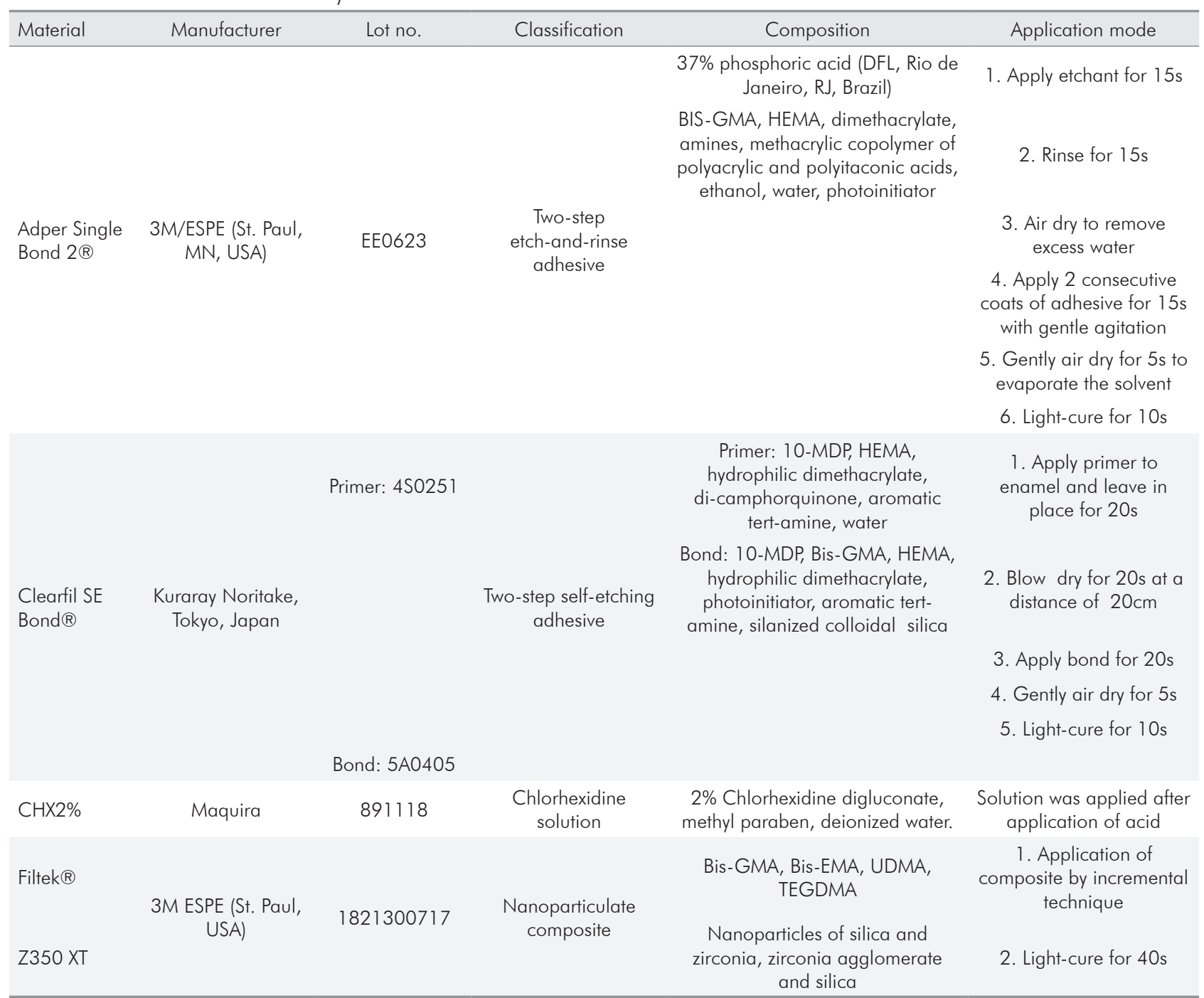

CHX, chlorhexidine. 
composite/tooth interface was scored according to criteria modified by Retief et al. ${ }^{12}$ (Table 2 ).

\section{Microtensile assay}

Sixty-four sound third molars were distributed into 16 groups $(n=4)$, according to artificial caries or non-caries induction, $\mathrm{CO}$ test emulsions for cleaning the dentin surface, and the adhesive systems. The two best CO emulsions - CO10\%X and CO10\% - were used for the microtensile test, in addition to the $\mathrm{CHX}$ and DW controls. Two different adhesive systems were used: conventional - Adper Single Bond® 2, and self-etching agent - Clearfil SE Bond. Each tooth was sectioned into 10 beams for measurement of microtensile bond strength, for a total of 40 beams per group. ${ }^{13,14}$ Group distributions and samples were performed according to Table 3 .

The healthy dentin surfaces of groups G1-G8 were produced on the dental occlusal surface by the Politriz polisher (AROTEC), equipped with 320 grit silicon carbide granulation at $500 \mathrm{rpm}$, under constant water-cooling, until exposure of a flat dentin surface with no remaining enamel. ${ }^{15}$ The apices were sealed with composite resin (Filtek ${ }^{\circledR}$ Z350 XT 3M ESPE)

Table 2. Score for penetration degree of tracer agent at composite/tooth interface

\begin{tabular}{lr}
\hline Score & Penetration degree \\
\hline 0 & Penetration of tracer agent into gingival wall, without reaching gingival / axial dihedral angle \\
1 & Penetration of tracer agent into gingival wall, reaching the dihedral angle gingival / axial \\
2 & Penetration of tracer agent into axial wall, without pulp envelopment \\
3 & Penetration of tracer agent into axial wall, with pulp wrapping \\
\hline
\end{tabular}

Table 3. Group and sample distribution according to healthy or carious substrate, test substance for dentin cleaning, and adhesive system.

\begin{tabular}{|c|c|c|c|c|}
\hline \multirow{2}{*}{ Group } & \multirow{2}{*}{ Dentin substrate } & \multirow{2}{*}{ Dentin cleaning substance } & \multirow{2}{*}{ Adhesive system ( $n=4$ teeth) } & \multirow{2}{*}{$\begin{array}{c}{ }^{*} \mathrm{~N} . \\
\text { beams / group }\end{array}$} \\
\hline & & & & \\
\hline G1 & & & Adper Single Bond $® 2$ & 40 \\
\hline G2 & & CO10\%x & Clearfil SE Bond $\AA$ & 40 \\
\hline G3 & & & Adper Single Bond $® 2$ & 40 \\
\hline G4 & Healthy & CO10\%Y & Clearfil SE Bond $\AA$ & 40 \\
\hline G5 & & & Adper Single Bond $\AA 2$ & 40 \\
\hline G6 & & $\mathrm{CH} \times 2 \%$ & Clearfil SE Bond $®$ & 40 \\
\hline G7 & & & 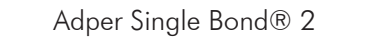 & 40 \\
\hline G8 & & DW & Clearfil SE Bond $®$ & 40 \\
\hline G9 & & & Adper Single Bond $® 2$ & 40 \\
\hline G10 & & CO10\%X & Clearfil SE Bond $\AA$ & 40 \\
\hline G11 & & & Adper Single Bond $® 2$ & 40 \\
\hline G12 & Carious & CO10\%Y & Clearfil SE Bond $®$ & 40 \\
\hline G13 & & & Adper Single Bond $® 2$ & 40 \\
\hline G14 & & $\mathrm{CH} \times 2 \%$ & Clearfil SE Bond $®$ & 40 \\
\hline G15 & & & Adper Single Bond $\AA 2$ & 40 \\
\hline G16 & & DW & Clearfil SE Bond $®$ & 40 \\
\hline
\end{tabular}

*Each tooth was sectioned into 10 beams. $\mathrm{CO}$, copaiba oil emulsion; $\mathrm{X}$ and $\mathrm{Y}$, different concentrations of preservatives; $\mathrm{CHX}$, chlorhexidine; DW, distilled water. 
after acid etching and application of the conventional adhesive system. Spherical steel drill no. 6 was used in deep rotation on the healthy dentin surface for 30 seconds to produce the smear layer, and the tooth roots were removed using a cutting machine.

Groups G9-G16 underwent artificial induction of caries according to the protocol by Sanabe et al. ${ }^{16}$ The dentin-infected layer was removed with a dentin curette, taking care to preserve caries-affected dentin, and the smear layer was produced by carbide spherical drill no. 6 in deep rotation for 30 seconds. The drill was replaced by a new one after preparation of every four teeth, and maximum carious dentin removal was established by visual and tactile inspection, using a probe. The roots of the teeth were removed with a cutting machine.

The surface treatment of all the groups was standardized, altering only the test solution applied after acid etching or before primer application, as stipulated for each specific group. A $20 \mu \mathrm{L}$ aliquot of the test solution was applied to the dentin surface for 60 seconds, followed by removal of excess material with sterile absorbent paper. Adper Single Bond® 2 or Clearfil SE Bond® ${ }^{\circledR}$ adhesive agents were then applied according to the manufacturer's guidelines. After completing dental restoration, the specimens were stored in DW and incubated at $37^{\circ} \mathrm{C}$ for $24 \mathrm{~h}$.

The specimens were adapted individually to the cutting machine for serial sectioning. The teeth were sectioned into slices measuring $1 \times 1 \mathrm{~mm}$ wide by $8 \mathrm{~mm}$ high, by using the low-speed diamond disc of a microtome (Isomet, Buehler Ltd., Bluff, USA), and by positioning the disc perpendicular to the tooth surface. ${ }^{14}$ The microtensile bond strength was measured by fixing each slice to the plate of a universal testing machine (Z020, Zwick GmbH \& Co. KG, Germany) using cyanoacrylate glue. The load was applied at a crosshead speed of 0.5 $\mathrm{mm} /$ minute until failure. The load at failure was recorded in Newtons $(\mathrm{N})$. The interface area of the broken piece was measured by a gauge. The load at failure in Newtons was divided by the enamel/ composite interface area into square millimeters $\left(\mathrm{mm}^{2}\right)$ to obtain the bond strength in megapascals (MPa). The samples were then inspected under a stereomicroscope (Olympus, SZX9, Iran) at 10x magnification to determine the mode of failure. The fracture pattern was classified into three failure groups, as follows: cohesive - within the tooth structure (dentin or cement), adhesive - within the composite (adhesive interface), and mixed (fracture line with more than one substrate). Pre-maturation fractures were considered as having a "zero" adhesion value.

\section{Statistical analysis}

The tooth and beams were considered the experimental unit for the microleakage and microtensile tests, respectively. The sample size for five teeth and 40 beams per group was estimated previously, considering a power higher than $80 \%$, a variation coefficient of $20 \%$, and a statistical significance level preset at $5 \%$. The normal distribution of the data was confirmed by the Kolmogorov-Smirnov test. The results for tracer penetration at the composite/ tooth interface (microleakage assay) were submitted to one-way ANOVA followed by the Tukey test, and the microtensile results were submitted to KruskalWallis or Mann-Whitney U-tests ( $\mathrm{p}<0.05)$, according to the dentin cleaning substance.

\section{Results}

The tracer penetrations at the composite/tooth interface, according to the microleakage assay results, are summarized in Table 4 . Dentin treated with $\mathrm{CO} 10 \% \mathrm{X}$ showed the lowest infiltration rate $(p<0.001)$, compared with dentin treated with other CO emulsions, and the $\mathrm{CHX} 2 \%$ and DW groups of the cervical section. It is noteworthy that the mesial and distal dentin, basically, showed no tracer penetration for any of the CO emulsions tested, or for the CHX2\% control group. Although the occlusal dentin presented marginal microleakage for all the dentin cleaning substances, the dentin treated with $\mathrm{CO}$ emulsions showed lower infiltration rates, although the difference among the groups was non-statistical.

The results of the microtensile assay, regarding healthy or carious substrate, dentin cleaning substance and adhesive system, are presented in Figure. In regard to the healthy dentin substrate, the 
adhesive strength was similar for the $\mathrm{CO}$ emulsions, and the CHX2\% and DW groups, for the same adhesive system. According to the carious dentin groups, dentin treated with $\mathrm{CO} 10 \% \mathrm{X}$ and $\mathrm{CO} 10 \% \mathrm{Y}$ presented greater adhesive strength than dentin treated with $\mathrm{CHX} 2 \%(\mathrm{p}<0.05)$ when the Adper Single Bond ${ }^{\circledR}$ system was used. On the other hand, carious dentin treated with the Clearfil SE Bond ${ }^{\circledR}$ system showed similar adhesive strength for the CO10\%X, $\mathrm{CHX} 2 \%$ and DW dentin cleaning groups, but higher than the CO10\%Y emulsion group ( $p<0.05)$. In addition, both healthy and carious dentin presented higher adhesive strength for the Adper Single Bond ${ }^{\circledR}$ adhesive system, compared with the Clearfil SE Bond ${ }^{\circledR}$ system $(\mathrm{p}<0.05)$, for all dentin cleaning substances analyzed.

The resulting fracture mode distribution by microtensile test is summarized in Table 5. The adhesive fracture was the most prevalent, followed by cohesive and mixed fracture, regardless of the dentin substrate, dentin cleaning substance or adhesive system analyzed. In regard to the adhesive fracture, in descending order:

a. Healthy dentin with Clearfil SE Bond: CO10\%X (100\%); CO10\% (92.5\%); DW (92.50\%); CHX $2 \%(80 \%)$.

Table 4. Tracer penetration at the composite/tooth interface in the different groups.

\begin{tabular}{|c|c|c|c|c|c|c|c|c|}
\hline \multirow{3}{*}{ Groups } & \multicolumn{8}{|c|}{ Sections } \\
\hline & \multirow{2}{*}{$\frac{\text { Cervical }}{\text { Mean }( \pm S D)}$} & \multirow{2}{*}{$p$-value } & Occlusal & \multirow{2}{*}{$\mathrm{p}$-value } & Distal & \multirow{2}{*}{$\mathrm{p}$-value } & Mesial & \multirow{2}{*}{$p$-value } \\
\hline & & & Mean $( \pm S D)$ & & Mean $( \pm \mathrm{SD})$ & & Mean $( \pm S D)$ & \\
\hline CO10\%x & $0.4( \pm 0.55)^{*}$ & & $0.4( \pm 0.55)$ & & $0.2( \pm 0.45)$ & & $0.2( \pm 0.45)$ & \\
\hline CO10\%Y & $2.6( \pm 0.89)$ & & $0.8( \pm 0.45)$ & & $0.0( \pm 0.00)$ & & $0.0( \pm 0.00)$ & \\
\hline CO10\%Z & $2.2( \pm 0.84)$ & $<0.01$ & $0.8( \pm 0.45)$ & $=0.102$ & $0.0( \pm 0.00)$ & $=0.431$ & $0.0( \pm 0.00)$ & $=0.570$ \\
\hline $\mathrm{CHX} 2 \%$ & $2.4( \pm 0.55)$ & & $1.2( \pm 0.45)$ & & $0.0( \pm 0.00)$ & & $0.2( \pm 0.45)$ & \\
\hline DW & $2.4( \pm 0.55)$ & & $1.4( \pm 0.89)$ & & $0.0( \pm 0.00)$ & & $0.0( \pm 0.00)$ & \\
\hline
\end{tabular}

${ }^{*} p<0.01$ compared with other groups of the cervical section; two-way ANOVA, Tukey's test. CO, copaiba oil emulsion; $X, Y$ and $Z$, different preservatives; CHX, chlorhexidine; DW, distilled water.

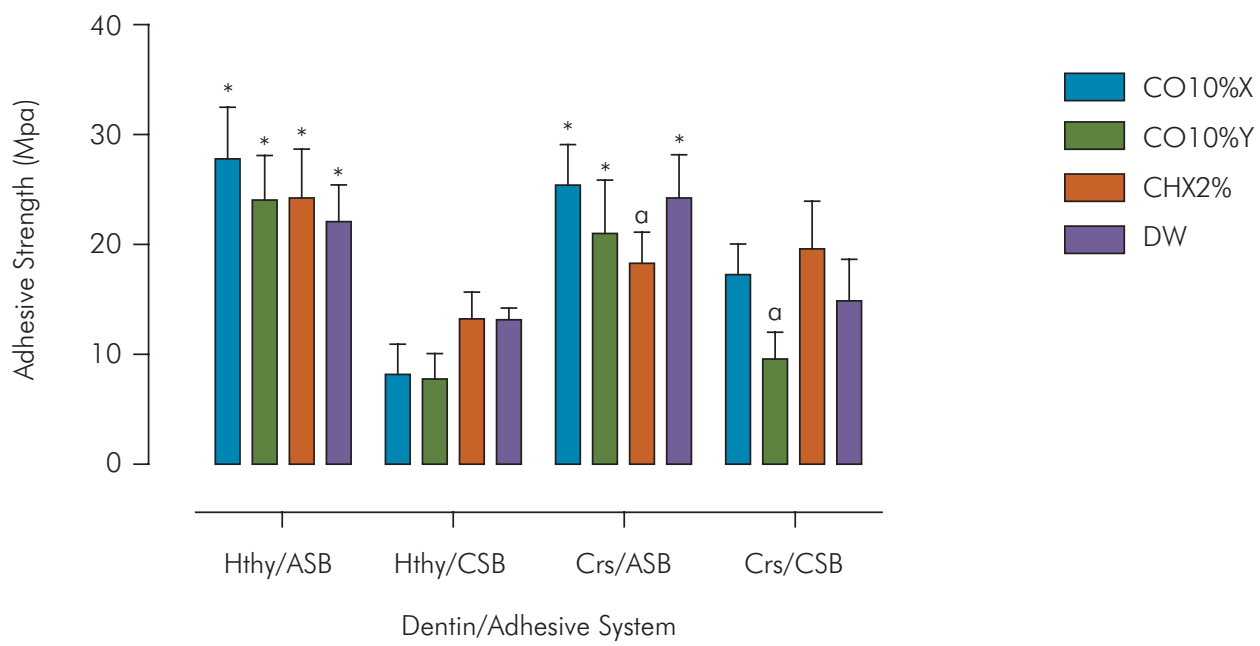

$\left.{ }^{*}\right) p<0.05$ compared with Clearfil SE Bond ${ }^{\circledR}(\mathrm{CSB})$, considering the same dentin substrate and dentin cleaning substance; Mann-Whitney U-test. (a) $p<0.05$ compared with other dentin cleaning substances, considering the same dentin substrate and adhesive system; Kruskal-Wallis test. CO, copaiba oil emulsion; X, and Y, different preservatives; CHX, chlorhexidine; DW, distilled water; Hthy, healthy dentin; Crs, carious dentin; ASB, Adper Single Bond $\AA 2$; CSB, Clearfil SE Bond ${ }^{\circledR}$.

Figure. Adhesive strength according to healthy or carious substrate, test substance for dentin cleaning, and adhesive system. 
Table 5. Fracture mode distribution according to healthy or carious substrate, test substance for dentin cleaning, and adhesive system.

\begin{tabular}{|c|c|c|c|c|c|c|c|}
\hline \multirow{3}{*}{ Dentin cleaning substance } & \multirow{3}{*}{ Dentin substrate } & \multicolumn{3}{|c|}{ 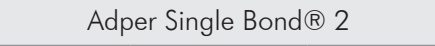 } & \multicolumn{3}{|c|}{ Clearfil SE Bond $\AA$} \\
\hline & & \multicolumn{6}{|c|}{ Fracture mode (\%) } \\
\hline & & A & C & M & A & C & M \\
\hline \multirow{2}{*}{ CO10\%x } & Healthy & 77.5 & 15 & 7.5 & 100 & 0 & 0 \\
\hline & Carious & 77.5 & 12.5 & 10 & 67.5 & 20 & 12.5 \\
\hline \multirow{2}{*}{ CO10\%Y } & Healthy & 77.5 & 12.5 & 10 & 92.5 & 5 & 2.5 \\
\hline & Carious & 77.5 & 12.5 & 10 & 82.5 & 12.5 & 5 \\
\hline \multirow{2}{*}{$\mathrm{CH} \times 2 \%$} & Healthy & 75 & 10 & 15 & 80 & 7.5 & 12.5 \\
\hline & Carious & 80 & 7.5 & 12.5 & 70 & 22.5 & 7.5 \\
\hline \multirow{2}{*}{ DW } & Healthy & 90 & 7.5 & 2.5 & 92.5 & 7.5 & 0 \\
\hline & Carious & 70 & 22.5 & 7.5 & 70 & 20 & 10 \\
\hline
\end{tabular}

A, adhesive; C, cohesive; M, mixed. CO, copaiba oil emulsion; $X$, and Y, different preservatives; CHX, chlorhexidine; DW, distilled water.

b. Carious dentin with Clearfil SE Bond®: $\mathrm{CO} 10 \% \mathrm{Y}$ (82.5\%); CHX 2\% (70\%); DW (70\%); CO10\%X (67.5\%).

c. Healthy Dentin with Adper Single Bond® 2: DW (90\%); CO10\%Y (77.5\%); CO10\%X (77.5\%); CHX 2\% (75\%).

d. Carious dentin with Adper Single Bond® 2: CHX 2\% (80\%); CO10\%Y (77.5\%); CO10\%X (77.5\%); DW (70\%).

\section{Discussion}

The current investigation has demonstrated that $\mathrm{CO}$ emulsion used as a dentin cleaning substance reduces marginal microleakage at the composite/ tooth interface, compared with other substances; consequently, the first null hypothesis was rejected. Moreover, $\mathrm{CO}$ emulsion interfered positively in the microtensile adhesive strength of the carious dentin group treated with the Adper Single Bond $\AA$ system; consequently, the second null hypothesis was rejected.

Class V cavity was the cavity preparation of choice for this study due to higher deflection dependent on its composition. Class V restorations are subject not only to masticatory forces, but also to small occlusal maladjustments or interferences often present and non-diagnosed, ${ }^{17}$ justifying why the microleakage test was performed on the Class $\mathrm{V}$ cavities.

Adhesion of polymer-based materials to dentin still poses a challenge, since dentin has a complex, predominantly tubular and moist substrate. Use of agents with biological properties, mainly antiproteolytic, can be recommended for dentinal cavities as an alternative to reduce these effects. ${ }^{3}$ Since collagen hydrolyzes under proteolytic action, a failure in the operative steps may compromise the hybrid layer quality, adversely interfering in the adhesive capability and bond strength of the restorative material to the dentin substrate. ${ }^{7}$

The disadvantage of most composites is polymerization-related contraction. This contraction may result in the formation of spaces between the tooth and the restorative material, leading to microleakage and consequent infiltration of bacteria, fluids and ions. Dentin microleakage is one of the main causes of restorative failure, preceded by marginal discoloration, postoperative sensitivity, recurrent caries, pulpal alterations and necrosis. ${ }^{6,18,19}$ Moreover, a smear layer is formed during cavity preparation, consisting of saliva, blood, bacteria and residual oils from rotating instruments. These residues can impair marginal adaptation and sealing, compromising restorative dental success. ${ }^{5,11}$

In this study, dentin cavities treated with emulsions based on $\mathrm{CO} 10 \% \mathrm{X}$ presented lower marginal infiltration than $\mathrm{CHX} 2 \%$, which is considered the gold standard, because of its substantivity, and its bacteriostatic and bactericidal properties. It should be pointed out that the $\mathrm{CO}$ emulsions had a positive effect on marginal adaptation and dentin bond strength, in that CO10\%X showed the lowest infiltration rate, especially in the cervical dentin, a result considered as satisfactory. Saffarour et al. ${ }^{9}$ 
observed smaller marginal infiltration in cavities treated with $\mathrm{CHX} 2 \%$ after acid etching by the same Adper Single Bond® system. According to Mooney, ${ }^{20}$ marginal infiltration is more pronounced in cervical margins without enamel. Copaiba oil emulsion, as a dentin biomodifier, has antibacterial activity and MMP-inhibiting properties, and may contribute to maintaining hybrid layer stability. This may be attributed to its action of preventing enzymatic hydrolysis of collagen due to its oily nature similar to that of mineral oil. ${ }^{3}$ This may have contributed to its positive effect on marginal adaptation.

In regard to the microtensile test, carious dentin was induced to evaluate the effect of the dentin cleaning substance at the composite/adhesive interface on different dentin substrates after cavity preparation. The bond strength was higher $(27.7 \pm 8.8 \mathrm{MPa})$ when using $\mathrm{CO} 10 \% \mathrm{X}$ on healthy dentin, together with the Adper Single Bond ${ }^{\circledR} 2$ adhesive system, corroborated by Pupo et al. ${ }^{21}$, who observed a strength of $30.1 \pm 9.1$ $\mathrm{MPa}$, using the same adhesive system. Resistance to the microtensile test performed on the Adper Single Bond ${ }^{\circledR} 2$ adhesive system, with previous acid conditioning, was superior in all of the groups studied, both in healthy and carious dentin, as corroborated by Cecchin et al. ${ }^{22}$

Evaluating conventional and self-etching adhesive systems, Karaarslan et al. ${ }^{23}$ observed that Adper Single Bond ${ }^{\circledR} 2$ featured higher strength than Clearfil SE Bond ${ }^{\circ}$, considering that the mean depth was $21.2 \mathrm{MPa}( \pm 3.3)$ and $19.9 \mathrm{MPa}( \pm 4.6)$, respectively, corroborating the results of the present study $(27.7 \pm 8.8 \mathrm{MPa}$ and $13.1 \pm 6.5 \mathrm{MPa})$, and those of Pouyanfar et al. ${ }^{14}$, who also observed the higher bond strength of Adper Single Bond ${ }^{\circledR}$ compared with Clearfil SE Bond ${ }^{\circledR}$, that is, a mean strength of 45.52MPa and 44.91MPa, respectively.

According to our results, use of the $\mathrm{CO}$ emulsion at $10 \%$, with $\mathrm{X} \%$ preservative $(\mathrm{CO} 10 \% \mathrm{X})$ on healthy dentin was entirely justifiable, since this $\mathrm{CO}$ emulsion presented the most significant strength results $(27.7 \pm$ $8.8 \mathrm{MPa})$, followed by CHX2\% $(24.2 \pm 9.5 \mathrm{MPa}), \mathrm{CO} 10 \%$ with preservative $\mathrm{Y} \%(24.1 \pm 8.05 \mathrm{MPa})$ and DW $(22.01$ $\pm 7.4 \mathrm{MPa}$ ). The same results were observed for carious dentin with the Adper Single Bond ${ }^{\circledR}$ system, in which case $\mathrm{CO} 10 \% \mathrm{X}$ also presented higher strength (25.4 \pm
7.7 MPa), followed by DW (24.2 $\pm 7.9 \mathrm{MPa}), \mathrm{CO} 10 \% \mathrm{Y}$ $(21.0 \pm 9.8 \mathrm{MPa})$, and finally CHX2\% (18.2 $\pm 6.9 \mathrm{MPa})$. A similar result was observed by Follak et al. ${ }^{24}$, who found the bond strength on carious teeth to be 22.4 $\mathrm{MPa}$, using the same system.

On the other hand, both healthy and carious dentin with the Clearfil SE Bond adhesive system presented the lowest bond strength values for all dentin cleaning substances. The penetrating power of the self-etch adhesive system (Clearfil SE Bond) in the dentinal tubules and in the intertubular dentin was lower than that of the etch-and-rinse adhesive (Adper Single Bond). This may explain the reduction in adhesive strength, ${ }^{3}$ and the difference in results between the adhesive systems presented in our study.

Fracture mode comparisons showed that $\mathrm{CO} 10 \% \mathrm{X}$ presented better results for adhesive fracture in healthy dentin (100\%), whereas CO10\%Y was similar to DW, followed by $\mathrm{CHX} 2 \%$. These results were corroborated by Ribeiro et al. ${ }^{25}$ in relation to the fracture type pattern. According to this author, the fracture pattern is more important than the nominal value of the adhesive strength. In this research, there was a predominance of adhesive and non-cohesive fractures, characterizing poor stress distribution at the adhesive interface. Pupo et al. ${ }^{21}$ revealed a predominance of adhesive fractures in relation to cohesive fractures, corroborating the results of the present study. Therefore, the microtensile test seems to be the best choice, because it distributes the tension in the adhesive interface in a more balanced manner, thus reducing the number of cohesive fractures in the substrate.

The emulsions also had good adhesive strength, considering that the conventional system used with healthy and carious dentin in the present study showed better results than that of other studies in the literature ${ }^{21,23,26}$.

According to Carrilho et al. ${ }^{27}$, the discovery that $\mathrm{CHX} 2 \%$ has not only antimicrobial but also antiproteolytic properties that act on MMPs has encouraged research on the subject. Conclusions infer that $\mathrm{CHX} 2 \%$ could stabilize the organic matrix of the cavity, thus contributing to the longevity of the adhesive restoration. In addition to its healing and 
antiproteolytic properties, $\mathrm{CO}$ is a phytotherapeutic substance that has antibacterial, antineoplastic and anti-inflammatory properties. ${ }^{2,28}$ Test results have shown that it is very similar to, if not better than, $\mathrm{CHX} 2 \%$. Bandeira et al. ${ }^{3}$ performed a study analyzing the morphological characteristics of the dentin and smear layer using Adper Single Bond ${ }^{\circledR}$ and Clearfil SE Bond adhesive systems in healthy and caries-affected dentin after using CO10\% emulsions. They observed that the dentin surface treated with $\mathrm{CO}$ emulsion presented no physical barriers to adhesive penetration, unlike the dentin surface treated with $\mathrm{CHX} 2 \%$, in which case, phosphate salts were found in both dentin types (carious and non-carious).

Therefore, the findings indicate that the $\mathrm{CO}$ emulsion offers promising results as an alternative to improve the quality of the hybrid layer, and to leave it homogeneous, regular and with a large number of resin tags, when used with conventional and selfetching adhesives. ${ }^{7}$ A limitation of this analysis was the lack of scientific evidence in the literature on the clinical use of copaiba-based emulsions, making comparison with other studies difficult. However, considering that the biological properties of $\mathrm{CO}$ emulsion evidenced so far have an advantage over CHX, it is believed that these emulsions can contribute positively to better adhesion of restorative materials to the dental structure. Further randomized control trials are required.

\section{Conclusion}

Based on the results, $\mathrm{CO}$ emulsion, as a dentin biomodifier, interfered positively in microleakage and improved the adhesive strength after acid etching with the Adper Single Bond $\AA$ adhesive system, or before applying the Clearfil SE Bond ${ }^{\circledR}$ self-etching system. In addition, since the adhesive fracture was the most prevalent, the $\mathrm{CO}$ emulsion also promoted adhesive strength when used with the conventional system in both healthy and carious dentin.

\section{Acknowledgements}

This study was financed by the National Council for Scientific and Technological Development - CNPq in Project MCT/CNPq/CT-Amazonia. Process no. 406457/2013-1.

\section{References}

1. Maciel MA, Pinto AC, Veiga Junior VF. Medicinal plants: the need for multidisciplinary scientific studies. Quim Nova. 2002 May;25(3):429-38. https://doi.org/10.1590/S0100-40422002000300016

2. Pieri FA, Silva VO, Souza CF, Costa JC, Santos LF, Moreira MA. Antimicrobial profile screening of two oils of Copaifera genus. Arq Bras Med Vet Zootec. 2012 Feb;64(1):241-4. https://doi.org/10.1590/S0102-093520120001000373.

3. Bandeira MF, Conde NC, Toda C, Casaroto AR, Lima G, Vasconcellos M, et al. Biopharmaceutical products and biomaterials of the Amazon region used in dentistry. Intechopen 2018 Dec. https://ddoi.org/105772/intechopen.82056

4. Black GV. A work in operative dentistry. Chicago: Medico-Dental; 1998.

5. Reis A, Loguércio AD. Materiais dentários diretos: dos fundamentos à aplicacão clínica. Santos: Santos; 2007.

6. Hegde MN, Vyapaka P, Shetty S. A comparative evaluation of microleakage of three different newer direct composite resins using a self-etching primer in class V cavities: An in vitro study. J Conserv Dent. 2009 Oct;12(4):160-3. https://doi.org/10.4103/0972-0707.58340

7. Moura LG. Análise morfológica da superfície dentinária hígida e afetada por cárie e da camada híbrida após aplicação de emulsão à base de óleo de copaíba (Copaifera multijuga Hayne) [dissertation]. Manaus: Universidade Federal do Amazonas, 2016.

8. Breschi L, Mazzoni A, Nato F, Carrilho M, Visintini E, Tjäderhane L, et al. Chlorhexidine stabilizes the adhesive interface: a 2-year in vitro study. Dental Materials. 2010 Apr;26(4):320-25. http://dx.doi.org/10.1016/i. dental.2009.11.153

9. Saffarpour A, Saffarpour A, Kharazifard MJ, Rad AE. Effect of chlorhexidine application protocol on durability of marginal seal of class $V$ restorations [PMID: 28127314]. J Dent (Tehran). 2016 Aug;13(4):231-7.

10. Mazzoni A, Pashley DH, Tay FR, Gobbi P, Orsini G, Ruggeri A Jr, et al. Immunohistochemical identification of MMP-2 and MMP-9 in human dentin: correlative FEI-SEM/TEM analysis. J Biomed Mater Res A. 2009 Mar;88(3):697-703. https://doi.org/10.1002/jbm.a.31920 
11. Bandeira MF, Lima GR, Lopes PP, Toda C, Venâncio GN, Lima GA, et al. Dentin cleaning ability of an amazon bioactive: evaluation by scanning electron microscopy. Open Dent J. 2016 May;10(1 Suppl-1, M5):182-7. https://doi.org/10.2174/1874210601610010182

12. Retief DH, Wendt SL, Bradley EL. Effect of adhesive thickness on the shear bond strength of Scotchbond 2/Silux to dentin. Am J Dent. 1989 Dec;2(6):341-4.

13. Costa AR, Garcia-Godoy F, Correr-Sobrinho L, Naves LZ, Raposo LH, Carvalho FG, et al. Influence of different dentin substrate (caries-affected, caries-infected, sound) on long-term $\mu$ TBS. Braz Dent J. 2017 Jan-Feb;28(1):16-23. https://doi.org/10.1590/0103-6440201700879

14. Pouyanfar H, Tabaii ES, Aghazadeh S, Nobari SP, Imani MM. Microtensile Bond Strength of composite to enamel using universal adhesive with/without acid etching compared to etch and rinse and Self-Etch Bonding agents. Open Access Maced J Med Sci. 2018 Nov;6(11):2186-92. https://doi.org/10.3889/oamims.2018.427

15. Ricci HA, Scheffel DL, Baldan LG, Santos FJ, Jafelicci M Jr, Hebling J. Influence of chlorhexidine on the wettability of sound and caries-affected dentin by an adhesive system. Rev Odontol Bras Central. 2011 Mar;20(53):119-24.

16. Sanabe ME, Costa CA, Hebling J. Exposed collagen in aged resin-dentin bonds produced on sound and caries-affected dentin in the presence of chlorhexidine. J Adhes Dent. 2011 Apr;13(2):117-24. https://doi.org/10.3290/i.jad.a19239

17. Russo EM, de Carvalho RC, Matson E, dos Santos RS. [Microleakage in class V cavities restored with esthetic materials, using different restorative techniques]. Pesqui Odontol Bras. 2001 Apr-Jun;15(2):145-50. https://doi.org/10.1590/S1517-74912001000200011

18. Ribeiro MGG, Vasconcelos DMP, Teixeira HM, Nascimento ABL, Costa SXS. Evaluation the marginal microleakage using different adhesive systems. Int J Dent. 2006 Jan;1(1):8-13.

19. Pereira SK, Souza JC, Souza LI, Trierweiller MI. Marginal microleakage: a challenge in adhesive restorative dentistry. Rev Ibero-AM Odontol Estet Dent. 2004 Mar;3(9):70-9.

20. Mooney B. Operatoria Dental. Madrid: Panamericana; 1999.

21. Pupo YM, Gomes GM, Martins G, Michel M, Gomes OM, Gomes JC. Influence of water storage time on microtensile bond strength of different adhesive systems on superficial and deep dentin. Braz Dent Sci. 2010 Aug;13(3):16-22. https://doi.org/10.14295/bds.2010.v13i1/2.8

22. Cecchin D, Farina AP, Spazzin AO, Galafassi D, Barbizam JV, Carlini-Júnior B. Influence of dentin depth on microtensile bond strength of total etching and self-etching adhesive systems. Rev Odonto Ciênc. 2008 Apr;23(2):150-5.

23. Sirin Karaarslan E, Yildiz E, Cebe MA, Yegin Z, Ozturk B. Evaluation of micro-tensile bond strength of caries-affected human dentine after three different caries removal techniques. J Dent. 2012 Oct;40(10):793-801. https://doi.org/10.1016/i.jdent.2012.05.013

24. Follak AC, Miotti LL, Lenzi TL, Rocha RO, Maxnuck Soares FZ. The impact of artificially caries-affected dentin on bond strength of multi-mode adhesives. J Conserv Dent. 2018 Mar-Apr;21(2):136-41. https://doi.org/10.4103/JCD.JCD_234_17

25. Ribeiro JC, Vale MS, Silva MM, Fernandes CA. The microtensile test in bond strength evaluation: fundamentals and applications. Rev Gaucha Odontol. 2013 Jul;61(0):497-504.

26. Medina AD, Paula AB, Puppin-Rontani RM, Naufel FS, Sinhoreti MA, Correr-Sobrinho L. Microtensile bond strength of indirect composite restorations using different combinations of resin-coating technique. Braz Dent Sci. 2012 Apr;15(2):63-70. https://doi.org/10.14295/bds.2012.v15i2.794

27. Carrilho MR, Carvalho RM, Sousa EN, Nicolau J, Breschi L, Mazzoni A, et al. Substantivity of chlorhexidine to human dentin. Dent Mater. 2010 Aug;26(8):779-85. https://doi.org/10.1016/j.dental.2010.04.002

28. Simões CA, Conde NC, Venâncio GN, Milério PS, Bandeira MF, da Veiga Júnior VF. Antibacterial Activity of Copaiba Oil Gel on Dental Biofilm. Open Dent J. 2016 May;10 Suppl-1, M6:188-95. https://doi.org/10.2174/1874210601610010188 